\title{
Stability of the Value of Gold.
}

$\mathrm{I}^{\mathrm{N}}$

a paper on "The Problem of the Future Value of Gold ", read before Section F (Economic Science and Statistics) of the British Association during the meeting at Cape Town, Mr. D. T. Jack stated that the general return to gold standard conditions within the last five years has again directed attention to the problem of stability in the value of gold over long periods.

The general problem of monetary reconstruction presents three distinct phases. The first is the cessation of inflation, the second involves the various readjustments consequent upon stabilisation, and the third and present phase involves the long period problem of the stability of the value of gold. The difficulties which arise from unstable price levels are now generally recognised. They generate artificial stimuli and checks to trade and industry ; they make for industrial friction, and they alter the real terms of long-dated debts. To Great Britain, a rise in the value of gold would be particularly detrimental, since it would restrict the recovery of British trade, more especially in view of the high proportion of overseas trade to total trade and the peculiar sensitiveness of international trade to a falling price level. It would increase the real burden of the national debt still further, while the necessity of deflating money costs of production would undermine the recent progress which has been made in negotiating satisfactory wage settlements.

The future value of gold is naturally governed by the conditions of demand for, and the supply of, gold. The world's gold production increased from 69 millions sterling in 1920 to $83 \frac{1}{2}$ millions sterling in 1928 , but it is still about 12 per cent below the 1913 level. In considering the probable future production of gold, it is necessary to allow for further technical improvements in mining which may make profitable the fuller utilisation of low-grade ores. There is also the consideration that gold production would receive a certain stimulus from an increase in the value of the metal. With regard to the Transvaal, taxation and transport charges are factors of some special importance.
More important factors in the position, however, arise from the side of demand rather than from the side of supply. Since the War, gold has not generally been restored into general circulation, and the widespread adoption of gold-exchange standard principles has made possible important economies in the monetary use of gold. It is important that full advantage should be taken of such economies now possible in the monetary use of gold. Among other things, that means that the reserve requirements of central banks should be restricted. It is necessary also to distinguish the free or effective gold reserves of central banks from the other part, which is immobilised as the minimum legal reserve against the ordinary internal note circulations. At the beginning of 1929 , only 35 per cent of the total gold holdings of the central banks of England, France, Germany, and the United States consisted of free or effective gold reserves. There has been a tendency also for certain European central banks to convert part of their reserves in foreign balances into gold for withdrawal to their own vaults, and the danger is that the countries in which these balances are held may find that the demands are so large that they are driven in selfprotection to raise their discount rates. For these reasons, central bank co-operation in the use of gold reserves is essentially desirable.

The recent proposals for the establishment of an international bank, if carried into effect, may further this co-operation and in that way will assist in the attempt to prevent any marked appreciation in the value of gold. But the specific proposal raises many difficulties. It is improbable that central banks would sacrifice their individual gold reserves to the management of any international institution. On the other hand, such an institution would facilitate co-operation in connexion with the payment of reparations, and that co-operation, if wisely and cautiously followed, might materially assist in the working out of a closer collaboration in connexion with international gold movements.

\section{Work of the Government Chemist.}

$\mathrm{T}$ those familiar with the intricacies of British law in so far as it demands the services of the chemist, and familiar also with the numerous kinds of chemical inquiry necessary for the proper functioning of the government departments, the Report of the Government Chemist upon the work of the Government Laboratory for the year ending Mar. 31, 1929 (London: H.M. Stationery Office, 1s, 6d. net), will prove both informative and suggestive. The work is of the most varied character, and the responsibilities are of the most diverse, whilst the list of 'other activities' of the Government Chemist, the Deputy Government Chemist, and other members of the staff affords ample evidence both of the importance of the laboratory in State and scientific affairs, and of the progressive spirit which pervades it.

Included in the report are statements which immediately arrest the attention of the general scientific reader. It is, for example, of interest to note that 37 samples of home-grown leaf tobacco, which is being experimentally cultivated in East Anglia and the south of England, were examined, and that of 32 samples of herb beer, ginger beer, etc., 14 contained alcohol ranging from 2 to 7 per cent of proof spirit. A sample of honey purporting to be of
British origin was shown, by the character of the pollen grains, to be foreign produce.

The investigations carried out by the laboratory are by no means confined to questions affecting the revenue, to matters involving the possibility of legal process, or to specifications for contracts. Thus, fifty-four samples of river water, muds, and effluents were examined to ascertain the condition of fishing streams from the point of view of fish life, and the effect of certain types of pollution, including that by road drainage, on fish and fish food. Further attention has also been given to the phenomenon of diurnal variation in the quantity of dissolved oxygen in rivers. Moreover, sea-water samples have been examined in connexion with a scheme of oceanic research carried out by the Ministry of Agriculture and Fisheries, and the Fishery Board for Scotland, acting in concert with the International Council for the Exploration of the Sea, in order that accurate data may be available for hydrographers and biologists.

It is also reported that examination of a material obtained during excavation at Rievaulx Abbey proved the substance to be spent oak bark, suggesting that part of the abbey building may at some period have been used as a tannery. A number of samples

No. 3130, VoL. 124] 
of wood and wood preservatives have been examined in connexion with experiments on the preservation of timber carried out by the Forest Products Research Laboratory, whilst methods for determining sulphur impurities in the atmosphere and dust in the air of rooms have been worked out. Seventythree documents, to which were affixed a large number of stamps, were examined and reported on in connexion with the fraudulent use of stamps, and numerous alterations were detected in betting books required for the assessment of betting duty, the original entries being ascertained in many cases.

Two passages from the Report relating to imported dairy produce may be quoted without comment: "Cheese. . . The results indicate that 50 per cent of the samples had been prepared from whole milk;
23 per cent from milk containing from three-quarters to the whole of its fat; 10 per cent from milk containing from one-half to three-quarters of its fat; and the remaining 17 per cent from milk containing from one-quarter to one-half of its fat. As, however, there are no regulations relating to the marking of skimmed or partially skimmed milk cheese, no exception could be taken to any of the importations." "Cream... . The samples could be classified into two main groups-one group of samples containing from 48 to 62 per cent of fat, and the other group from 18 to 30 per cent. Two samples, however, contained only 11.9 and 12.9 per cent respectively. There is no standard for cream in this country, and no exception could be taken to the samples on account of low proportion of fat."

\section{General Paralysis and Malaria.}

$\mathrm{T}$ HE Board of Control has issued a report ${ }^{1}$ on the treatment of general paralysis by induced malaria, the most outstanding development in psychiatry of the last ten years. For the better appreciation of this important subject, Sir Hubert Bond has written in the form of a preface a historical review of the disease, based on Prof. G. M. Robertson's account. The report itself is by Surgeon RearAdmiral Meagher, and is the result of his investigations of certified cases admitted to county, district, and county borough mental hospitals in Great Britain between July 1922 and July 1927.

The results of treatment during the years 1922-1924 are the most valuable, the three to five year interval allowing a more accurate estimation to be made than in the case of subsequent years. The cases treated prior to the end of 1924 numbered 438 ; the results as ascertained at the end of 1927 were that $43 \cdot 6$ per cent were dead, 31.7 per cent remained in hospital, and $24 \cdot 7$ per cent were at liberty. A similar survey of 1173 patients certified during 1923 and 1924 and not treated by malaria showed that 86.6 per cent died, 10 per cent remained in hospital, and $3 \cdot 4$ per cent were discharged. The mental and physical state of those remaining in hospital was found to be much better in treated cases than in untreated.

After considering possible sources of error it is shown conclusively that malarial treatment tends to prolong life, to improve the condition of those who must remain under care, and to increase very greatly

1 Board of Control (England and Wales). General Paralysis and its Treatment by Induced Malaria. By Surgeon Rear-Admiral E. T. Meagher. Pp. 88. (London: H.M. Stationery Office, 1929.) 2s. net. the proportion of patients who can be discharged from certificate, and the probability that such discharge will be a success. The results during subsequent years confirm these findings. Altogether, the effect of treatment in 1597 cases is reported; as ascertained at the end of 1927, 541 died, 652 remained in hospital, and 404 were at liberty.

Attention is directed particularly to the mortality resulting from malaria. A relatively large number of deaths take place within two months of inoculation. According to the experience of the Wagner-Jauregg Clinic, this is avoidable, and efforts are being made at various mental hospitals in Great Britain to reduce the mortality. There is evidence also that the administration of antisyphilitic drugs in conjunction with malaria might lead to even better results. It is generally agreed that the best results from malarial therapy are obtained in early cases, but there is little or no provision for giving treatment until the patient becomes certifiable and can be sent to a mental hospital. An extension of facilities, either by alteration of the law relating to insanity or by the establishment of other treatment centres, will be necessary before the best results are obtained.

Rear-Admiral Meagher and the Board of Control are to be congratulated on the production of such an important account of malarial treatment. It demonstrates what can be done by utilising the facilities which the Board have for studying such problems, and it is to be hoped that these might be applied to the further investigation of a disease concerning the essential nature of which, as is quoted in the preface, we are quite in the dark.

\section{Prehistoric Macedonia.}

TN Antiquity for September, Mr. W. A. Heurtley, Director of the British School of Archæology in Athens, summarises the evidence bearing on the prehistory of Macedonia which has been acquired by the excavations carried out in recent years by the School, by Mr. S. Casson, and by the Archæological Service of the French Army in 1917-19. The sites examined are situated in the Vardar Valley, the neighbourhood of Salonika, the Valley of the Haliakmon, the Lankada Valley, and Chalcidice. An Early Iron Age cemetery at Patele was also excavated by Russian archæologists before the War, and a neolithic site at Olynthus by American excavators in 1928

The neolithic culture resembles the Second Thessalian period, but as it seems to be earlier the movement would appear to be from north to south. At the beginning of the Bronze Age, Central Macedonia and Chalcidice were colonised by people coming from Asia Minor, evidently in search of gold. The trade relations were not with the Agean, but with Troy, the Black Sea, and southern Russia. In the Middle Macedonian period, central Macedonia and Chalcidice diverge. In both the Anatolian culture was interrupted, central Macedonia falling under the influence of her northern neighbour, while Chalcidice was overrun by the Minyans, who were thought to have come from Troy, were possibly Indo-European, and may have introduced an Aryan speech into Chalcidice and Greece.

In central Macedonia, on the other hand, the pottery suggests Danubian pottery of an earlier date, or it may have developed locally from the incised style of the previous period. Some passed into Thessaly, the emigrant Macedonians creating the culture of the

$$
\text { No. } 3130 \text {, VoL. 124] }
$$

